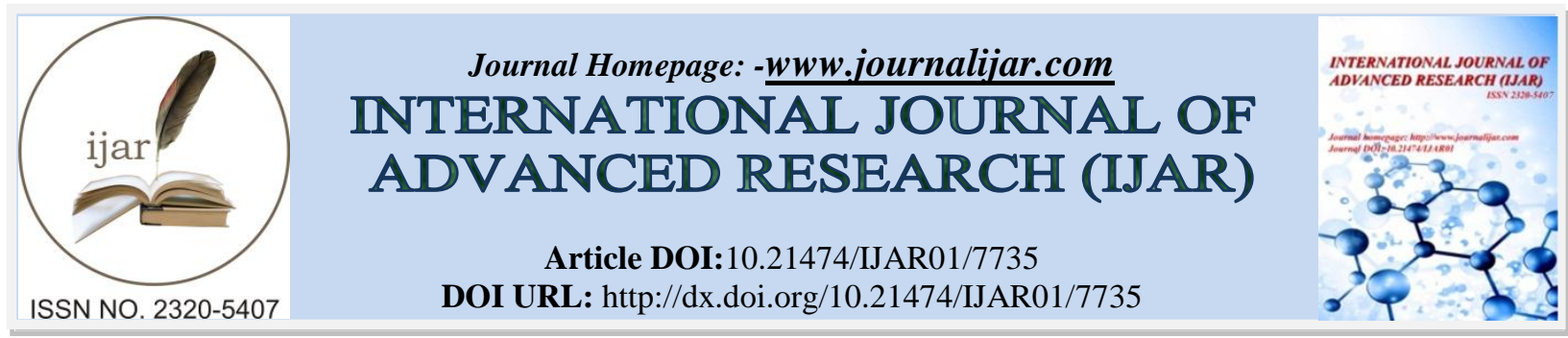

RESEARCH ARTICLE

\title{
THE EFFECTS OF AGES ON THE SOME MECHANICAL PROPERTIES OF Phyllostachys pubescens BAMBOO.
}

Tran Lam Tra.

Dean of School of Industry and Architecture, VietNam National University of Forestry, DongNai, VietNam.

\section{Manuscript Info} .........................

Manuscript History

Received: 23 July 2018

Final Accepted: 29 August 2018

Published: September 2018

Keywords:-

Ages, effect, mechanical properties,

Phyllostachys pubescens.

\section{Abstract}

This paper formulates and reviews Indicators of mechanical strength of bamboo such as: vertical compression strength, vertical tensile strength, radial direction bending strength, tangent direction bending strength...is one of the important bases for determining the time to exploit rationally and effectively. In this article, values of mechanical strength have been mentioned above, when the test sample moisture reaches $12 \%$, by different ages of Phyllostachys pubescens have been studied. The collection of test sample, determine the mechanical properties of bamboo is determined according to standard GB / T 15780 - 1995 of China - Testing methods for physical and mechanical properties of bamboos. According to research results, when the age of Phyllostachys pubescens varies from 1 to 6 years old, the vertical compression strength, vertical tensile strength, radial direction bending strength, tangent direction bending strength,... tend to increase and reach the maximum value when Phyllostachys pubescens at the age of 5 years. When the age of 6 years, Indicators of this mechanical properties tends to decrease.

Copy Right, IJAR, 2018,. All rights reserved.

\section{Introduction:-}

Bamboos are a collection of plants belonging to the phylum (Poaceae or Gramineae). Bamboo species are abundant, diverse and widely distributed all over the world, especially in Asia, including Vietnam. Bamboos are easy to grow, grow fast, early for exploitation, easy to process, should be used for many purposes. They are of great value to the national economy and the people's life. Since ancient times, bamboo has brought people as a main material for making building materials, making houses such as: house pillar, beams, rafters of homes ..., Daily necessities such as tents, beds, tables, chairs, beds, baskets, chopsticks. Today, along with the development of science and technology, advances in manufacturing techniques, people have used bamboo to make other materials such as: Bamboo flooring, composite materials from bamboo, laminboard ... . Besides, bamboo is also the ideal material for paper production. Bamboo stems contain high fiber content (40-60\%), fiber length is about $1.5-2.5 \mathrm{~mm}$ (maximum $5 \mathrm{~mm}$ ), is a good material for paper production (Nguyen Hoang Nghia FSIV 2005). In addition to the use of bamboo for these purposes, some bamboo species also eat bamboo shoots such as: bamboo shoots, .... . This is a good source of food and also an important source of income for mountainous people.

In Vietnam, there are not many researches on bamboo materials, in research papers, syllabus, etc..., the bamboo section is very small and does not correspond to the popularity of its use. In studies related to taxonomy, the majority of these are independent studies such as morphology, anatomy, identification, distribution and use of some 
types of bamboo. For example, the book "The Name of Vietnamese Forests" by Nguyen Tich and Tran Hop, published in 1971, mentions some useful bamboo species commonly used by villagers such as Buong, Dang, Dien.

Recently, in 2005, author Nguyen Hoang Nghia has researched and published the book "Bamboo Vietnam", this book has described to push the most number of genus and bamboo species in VietNam. The author presents a list of genus and genus species in Vietnam, including 25 genera and 216 species, some characteristic features of 191 species of bamboo in Vietnam (description of underground tree, length and diameter of the trunk, leaf length and width, number of branches, length, etc.).

The research on processing and preservation of bamboo mainly with the researches: Research on the physical and chemical properties of some bamboo species to be processed and preserved for use in household production, construction and paper industries. For example: Research on layout of production lines for bamboo processing (Le Van Hy 1971); Principles of technology for production of bamboo fiber boards and eucalyptus wood in the form of raw pulp by the author Hua Thi Huan 1993. In 2001, Nguyen Thi Bich Ngoc studied the technique of bamboo preservation treatment by replace the resin method. The author has given the scientific basis of the preservation process, the relationship between the chemical composition of bamboo and the preservation process... . Previously, in 2000, author Nguyen Thi Bich Ngoc studied the influence of bamboo structure on the ability of preservative (Journal of Science and Technology, 9/2000), the purpose of this study was to determine the ability of preservative of bamboo in different directions, the ability of preserving the preservation of the bamboo internode and the node, the ability to absorb the different positions on the bamboo (root, middle and tops). Research has given some different differences between Bambusa bambos and Dendrocalamus membranaceus to the ability to absorb preservatives. The results of the study contributed to explain the difference in the ability of preserving the preservation of bamboo in different directions and between these two species. In 2004, two authors Bui Chi Kien and Tran Tuan Nghia studied the possibility of using bamboo sawdust to produce lacquer trays, plates to exported by technology pressed into shape. The research results have produced 500 plates, trays from bamboo sawdust in shape, size, mechanical durability and other technological indicators to meet the requirements for lacquer finishing. quality products for export.

Research on characteristics, characteristics of bamboo has some typical research such as: In 2017, two authors Dang Xuan Thuc and Vu Manh Tuong studied the volumetric volume fluctuations and shrinkage of Dendrocalamus giganteus. In this paper, dry volume, volume, radial shrinkage, tangential shrinkage and volume shrinkage according to the age of the tree and the location of the tree was studied. In 2013, authors Pham Thanh Trang, Bui Dinh Duc and Nguyen Thi Thu studied morphology and anatomy of Phyllostachys nigra Munro in Sapa Lao Cai VietNam. In this study, morphological characteristics such as culm, auricle, leaf,..., the anatomical characteristics of Phyllostachys nigra Munro have been described.

In general, the researches on bamboo in Vietnam are focused on characterizing the morphology, structure, subspecies and some other areas of preservation and processing... Research on bamboo harvesting time has not been paid much attention; Determining the time and age of bamboo harvesting is mainly based on the experience of folk. Based on understanding the relationship between age and mechanical properties of bamboo, to do the basis for determining the most appropriate bamboo age for harvesting and production is practical and meaningful.

\section{Materials And Methods Of Research:- Materials}

The experiment was carried out on bamboo specie (Phyllostachys pubescens Mazel ex Hiep Lehaie), taken from the mountainous area north of Cao Bang province. In Vietnam, this bamboo species is also called Truc sao, Truc to... . This is a type of bamboo with no spines, small leaves, scattered single trees - the underground body of the whip, straight upright - no curved. Medium size tree: $10 \mathrm{~m}$ high bamboo stem, $5 \mathrm{~cm}$ diameter, $25 \mathrm{~cm}$ internode, $0.6 \mathrm{~cm}$ thick body wall. 


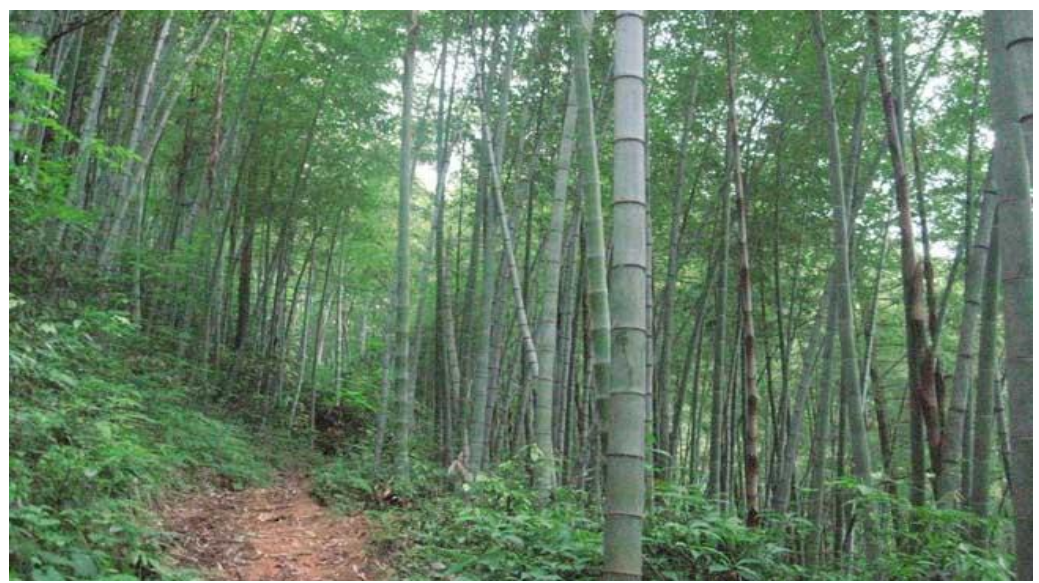

\section{Method}

Figure 1:-Phyllostachys pubescens

Collection of specimens, determination of mechanical properties of bamboo was determined according to GB / T 15780 - 1995 standard of China - Test method of mechanical and physical properties of bamboo.

After cutting down the experimental bamboo, record the diameter at chest height, height and height under the stems. Each tree from the node away the ground about $1.5 \mathrm{~m}$, up to the top, cut to pick up a section about $2.0 \mathrm{~m}$. The bamboo that height under the branches is relatively low, the diameter at the chest is relatively small, can be from the position of the node away the ground about $1 \mathrm{~m}$, upward, cut out a piece of about $2.0 \mathrm{~m}$.

Create a test sample, Each bamboo length is about $2.0 \mathrm{~m}$ of each bamboo root, choose two bamboo tubes no defects, green, unscathed, length between nodes is $200 \mathrm{~mm}$ or more. Bamboo tube on the bottom, in the east, south, west, and north directions split into $15 \mathrm{~mm}$ and $30 \mathrm{~mm}$ bamboo bars, each direction a bar. Bars of $15 \mathrm{~mm}$ in width are used for sample shrinkage, density, bending strength and elasticity. The bars are $30 \mathrm{~mm}$ wide used for longitudinal compressive strength testing, and longitudinal sliding strength. Bamboo tube on the top, in the east, west, and north directions split into bars of $15 \mathrm{~mm}$ in width, each direction is a bar, used to create longitudinal tensile strength test. If the length between the nodes is less than $280 \mathrm{~mm}$, allow the tip of the specimen, the position of the clamp to hold $60 \mathrm{~mm}$ long may contain the node.

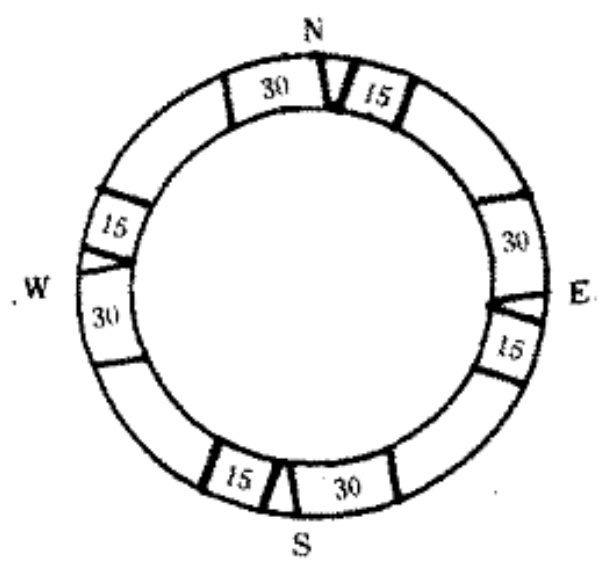

Figure 2.2.:-Method for producing test specimens test bending strength and vertical compression strength

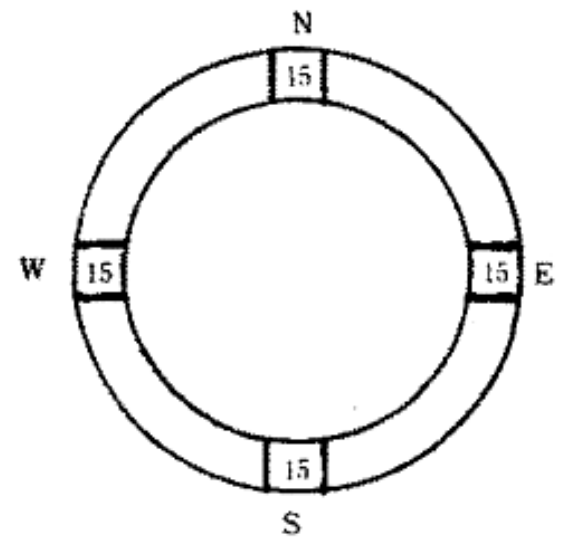

Figure 2.3.:-Method for producing test specimens test longitudinal tensile strength

The cross section of the sample shall be perpendicular to the vertical, Double curved sides need to ensure that the bamboo outer and bamboo intestines are in their original state, Radial face and head face should be perpendicular to each other. Each test specimen should be clearly numbered.

Accuracy of the sample, error on the length is $\pm 1,0 \mathrm{~mm}$, error on width is $\pm 0,5 \mathrm{~mm}$, On the whole length of the test specimen, the relative deviation of the width shall not exceed $0,2 \mathrm{~mm}$. 
The test strip is dried by air to make a test sample, then put in the room temperature and humidity does not change, or can be placed in a box with constant temperature and humidity, the temperature is $20 \pm 2{ }^{\circ} \mathrm{C}$, the relative humidity is $65 \pm 5 \%$, Adjustment of the water content in the equilibrium sample is $12 \%$.

The size of the sample is as follows:

- Longitudinal compressive strength test specimens: 20 x 20 x t (mm);

- Longitudinal tensile strength test specimen: $15 \times 250 \times \mathrm{t}(\mathrm{mm})$;

- Static bending strength test pattern: $10 \times 300 \times \mathrm{t}(\mathrm{mm})$.

In it: $t$ is the thickness of the bamboo.

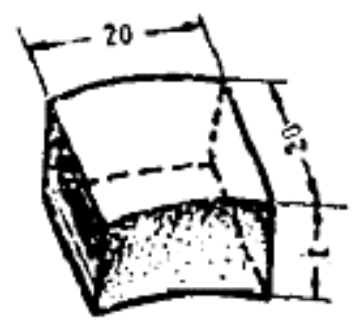

Figure 2.4:-Longitudinal compressive strength test specimens

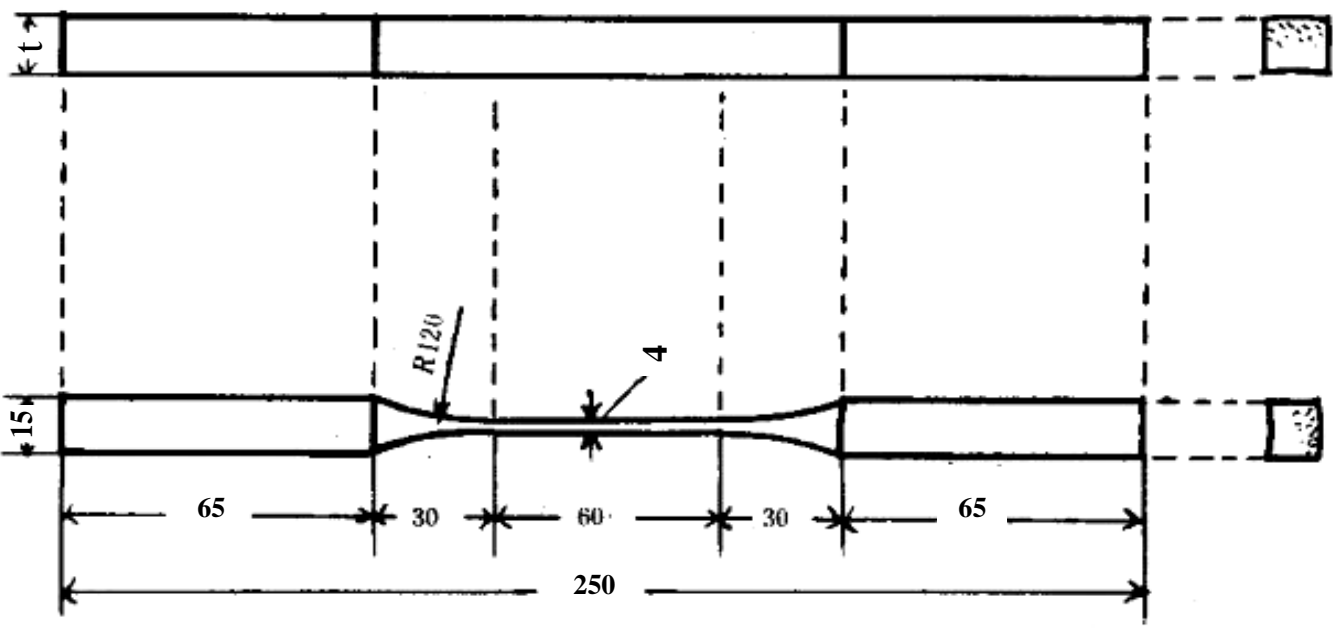

Figure 2.5.:-Longitudinal tensile strength test specimen
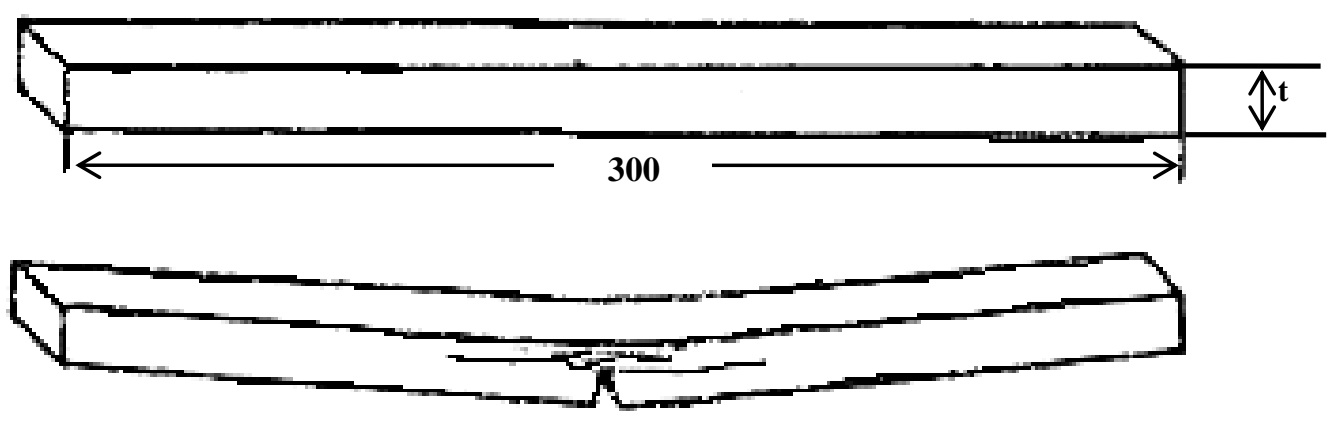

Figure 2.6.:-Static bending strength test pattern

Determination of vertical compression strength $\left(\sigma_{\mathrm{nd}}\right)$ :

$$
\sigma_{\mathrm{nd}}=\frac{\mathrm{P}_{\max }}{\mathrm{b} \times \mathrm{t}} ;
$$

Determination of vertical tensile strength $\left(\sigma_{\mathrm{kd}}\right)$ : 


$$
\sigma_{\mathrm{kd}}=\frac{\mathrm{P}_{\max }}{\mathrm{b} \times \mathrm{t}} ;
$$

Determination of static bending strength (MOR):

Static bending strength tangential direction:

$$
M O R_{\mathrm{tt}}=\frac{3 \mathrm{P}_{\max } \mathrm{L}}{2 \mathrm{t} \times \mathrm{b}^{2}} ;
$$

Static bending strength radial direction:

$$
M O R_{\mathrm{xt}}=\frac{3 \mathrm{P}_{\max } \mathrm{L}}{2 \mathrm{~b} \mathrm{x} \mathrm{t}^{2}} ;
$$

In the formulas $2.1,2.2,2.3,2.4, \mathrm{P}_{\max }$ is the maximum load $(\mathrm{kg}), \mathrm{b}$ is the specimen width (cm), $\mathrm{t}$ is bamboo wall thickness $(\mathrm{cm}), \mathrm{L}$ is the distance between the two pillars on the test device.

\section{Research results and discussion:-}

3.1. Longitudinal compression strength (MPa) with different ages of Phyllostachys pubescens

\begin{tabular}{|l|l|l|l|l|l|}
\hline \multirow{2}{*}{ TT } & \multicolumn{5}{|l|}{ Ages } \\
\cline { 2 - 6 } & $\mathbf{2}$ years & $\mathbf{3}$ years & $\mathbf{4}$ years & $\mathbf{5}$ years & $\mathbf{6}$ years \\
\hline 1 & 52,7 & 64,8 & 65,9 & 68,7 & 61,3 \\
\hline 2 & 64,7 & 70,6 & 71,3 & 70,4 & 69,0 \\
\hline 3 & 54,4 & 62,4 & 65,1 & 67,0 & 62,6 \\
\hline 4 & 47,5 & 58,1 & 60,3 & 65,4 & 63,1 \\
\hline 5 & 53,4 & 56,6 & 62,8 & 63,9 & 57,4 \\
\hline Average value & $\mathbf{5 4 , 5}$ & $\mathbf{6 2 , 5}$ & $\mathbf{6 5 , 1}$ & $\mathbf{6 7 , 1}$ & $\mathbf{6 2 , 7}$ \\
\hline
\end{tabular}

Results from the table show that: Longitudinal compression strength of Phyllostachys pubescens increases with increasing age. When the age of Phyllostachys pubescens reaches 5 years, the longitudinal compression strength reaches the highest value, at 6 years of age this value decreases compared to the age of 5 years.

3.2. Longitudinal tensile strength (MPa) with different ages of Phyllostachys pubescens.

\begin{tabular}{|l|l|l|l|l|l|}
\hline \multirow{2}{*}{ TT } & Ages & \multicolumn{4}{l|}{} \\
\cline { 2 - 6 } & $\mathbf{2}$ years & $\mathbf{3}$ years & $\mathbf{4}$ years & $\mathbf{5}$ years & $\mathbf{6}$ years \\
\hline 1 & 149,1 & 175,5 & 185,4 & 195,8 & 178,3 \\
\hline 2 & 182,6 & 193,9 & 205,4 & 197,8 & 181,9 \\
\hline 3 & 155,8 & 185,1 & 189,1 & 188,5 & 173,1 \\
\hline 4 & 134,5 & 183,9 & 181,9 & 183,4 & 169,6 \\
\hline 5 & 160,8 & 191,1 & 187,6 & 181,0 & 166,8 \\
\hline Average value & $\mathbf{1 5 6 , 6}$ & $\mathbf{1 8 5 , 9}$ & $\mathbf{1 8 9 , 9}$ & $\mathbf{1 8 9 , 3}$ & $\mathbf{1 7 3 , 9}$ \\
\hline
\end{tabular}

Based on the data we see that: As the age of Phyllostachys pubescens increases from 2 to 5 years, the tensile strength of Phyllostachys pubescens is also increasing. Longitudinal tensile strength of Phyllostachys pubescens is highest when Truc sao is 4-5 years old.

3.3. Static bending strength radial direction (MPa) with different ages of Phyllostachys pubescens.

\begin{tabular}{|l|l|l|l|l|l|}
\hline \multirow{2}{*}{ TT } & Ages & $\mathbf{3}$ years & $\mathbf{4}$ years & $\mathbf{5}$ years & $\mathbf{6}$ years \\
\cline { 2 - 6 } & $\mathbf{2}$ years & 123,9 & 118,5 & 136,8 & 116,9 \\
\hline 1 & 104,5 & 129,6 & 136,4 & 129,0 & 126,3 \\
\hline 2 & 119,8 & 121,3 & 124,1 & 128,1 & 120,3 \\
\hline 4 & 106,5 & 113,3 & 120,9 & 120,8 & 118,2 \\
\hline 5 & 100,8 & 118,0 & 121,1 & 126,4 & 120,2 \\
\hline
\end{tabular}




\begin{tabular}{|l|l|l|l|l|l|}
\hline Average value & 106,6 & 121,2 & 124,2 & 128,2 & 120,4 \\
\hline
\end{tabular}

3.4. Static bending strength tangential direction (MPa) with different ages of Phyllostachys pubescens.

\begin{tabular}{|l|l|l|l|l|l|}
\hline \multirow{2}{*}{ TT } & Ages & $\mathbf{3}$ years & $\mathbf{4}$ years & $\mathbf{5}$ years & $\mathbf{6}$ years \\
\cline { 2 - 6 } & $\mathbf{2}$ years & 143,5 & 137,6 & 139,3 & 121,3 \\
\hline 1 & 85,5 & 144,7 & 140,5 & 140,1 & 139,5 \\
\hline 2 & 128,0 & 134,9 & 136,2 & 137,5 & 128,4 \\
\hline 3 & 107,6 & 122,7 & 132,2 & 129,6 & 120,6 \\
\hline 4 & 106,4 & 124,8 & 130,5 & 136,8 & 128,3 \\
\hline $\begin{array}{l}\text { Average } \\
\text { value }\end{array}$ & 114,5 & $\mathbf{1 3 4 , 1}$ & $\mathbf{1 3 5 , 4}$ & $\mathbf{1 3 6 , 7}$ & $\mathbf{1 2 7 , 6}$ \\
\hline
\end{tabular}

As the age of Phyllostachys pubescens increased from 2 to 5 years old, Static bending strength tangential direction, Static bending strength radial direction tends to increase and reached the maximum value when the age of Phyllostachys pubescens reached 5 years old. By the age of 6 years, these values tend to decrease.

\section{Conclusion:-}

The mechanical properties of Phyllostachys pubescens: Longitudinal compression strength, Longitudinal tensile strength, Static bending strength radial direction, Static bending strength tangential direction, tends to increase rapidly as age increases from 2-5 years old; transition to a period of 6 years of age, These indicators of the mechanical properties of Phyllostachys pubescens are on the downward trend and reached the highest value when 5 years old. This can be explained by the growth and development of Phyllostachys pubescens, from 2 to 4 years old, the cells of Phyllostachys pubescens are in the stage of development, the mechanical properties of the cellular fiber, the linkage between them has not reached maturity, stability and stability. Moving on to the 5-year-old stage, these properties of Phyllostachys pubescens reach maturity. At 6 years of age, the structure of Truc sao begins to age, reducing some of its mechanical properties.

In order to have more scientific basis for efficient exploitation and use of Phyllostachys pubescens, Further studies on the mechanical properties of different sites on the same tree should be made, mechanical properties change under different growth conditions....

\section{References:-}

1. Do Van Ban (2005). Research about how to determine some of the physical properties of bamboo based on a small, non-defect-free sample. Vietnamese Journal of Forestry Science dated 16th July 2005;

2. Vu Huy Dai, Ta Thi Phuong Hoa, Vu Manh Tuong, Nguyen Tu Kim, Do Van Ban (2016). Textbook of Wood Science, Agricultural publisher, Ha Noi;

3. Nguyen The Nang (2005). Survey on the physical and mechanical properties of some bamboo species, Graduation thesis 2005 - HCMC University of Agriculture and Forestry;

4. Nguyen Hoang Nghia, Tran Van Tien (2009). Results of the list of bamboos in Vietnam, Vietnamese Forest Science Journal dated 20 April 2009;

5. Dang Xuan Thuc, Vu Manh Tuong. Volume fluctuations and shrinkage of the Dendrocalamus giganteus, Journal of Forest Science and Technology No. 1-2017;

6. National Standard of the People's Republic of China. GB/T 15780-1995. Method of testing the mechanical and physical properties of bamboos;

7. Yang Yun Fang, Yu You Ming, Fang Wei, Zhang Ai Liang, Han Chun, Study on physico - mechanical properties of culm - wood of Phyllostachys tridenscens, Journal of zhejiang Forestry College, 1998, 15 (2):158163. 